\title{
Planet Play: Designing a Game for Children to Promote Environmental Awareness
}

\author{
Maria Goncharova, University of Alberta, Canada
}

\begin{abstract}
Due to a progressive deterioration of our planet and its resources, environmental education has become crucial and children should be trained to understand environmental issues at an early age so they can cultivate positive change in the future. Children attending Alberta-based schools are introduced to ecological conservation issues in the fourth grade through an inquiry-based, activelearning curriculum. This study combines research in child development \& educational strategies with environmentally related issues into a game that promotes active learning. Data for the study is gathered in a qualitative manner, introducing child participants to existing environmental games and collecting their feedback into graphic organizers. A prototype of an environmental education game that combines various styles of play will then be designed based on the gathered data. The game aims to explore concepts, scenarios, and strategies of environmental preservation, encouraging children to become active participants in preserving the planet and promoting environmentally responsible behavior.
\end{abstract}

Keywords: Play; Environmental Education; Active Learning; Design of Educational Games. 


\section{Introduction}

A continuous deterioration of our planet and its resources has triggered policy makers and businesses to somewhat reconsider their harmful actions and implement certain changes into their originally designed systems and policies (Takala, 1991). However, this has been only partially effective in preserving the environment for future generations, seeing that these actions are neither universal, nor fully put into effect; according to Takala (1991), any potential for a significant shift towards environmental consciousness is hampered by policy-makers who are initially and foremost preoccupied with rapid economic growth - an idea mostly conflicting with sustainability and cautious treatment of the planet and its resources. Research in the field suggests that "any great changes in the behavior of ...persons, industry, and government" (Takala, 1991, p. 587) where environmental awareness and positive change are concerned, would have to begin with the individual, at the earliest coherent stages of their development.

Moreover, "necessary changes in people's attitude to the environment can occur as a result of general education, carried out on a mass scale, available for all social groups and generations" (Domka, 2005, p.258). Environmental education is a prerequisite for environmental awareness to transpire; yet it is still not ubiquitously offered and practiced on a global scale, being the privilege of school curriculums only in economically developed nations (Gajus-Lankamer, 2004). Reiterating Domka, environmental education and hence environmental awareness should be available to anyone and everyone, beginning with and focusing primarily on elementary school children - their young age making them "very susceptible to the influence of teachers" (2005, p.258) and the material taught to them both at school and at home. Furthermore, the way information is presented to children, influences both their initial understanding of the material and its future retention. Traditional teaching methods involving "mechanically follow[ing] a set of steps or read[ing] and hear[ing] about things learned and done by others" are not as effective a learning tool, as active or inquiry-based systems of education (Elementary Science, 1996, p.A2).

This graduate-level study is based out of Alberta, Canada, using the Alberta Education science curriculum and the framework devised by the Pan Canadian Protocol for Collaboration on School Curriculum, which consist of an inquiry-based approach to learning. According to the 
Alberta Education curriculum designers, "young children are natural inquirers and problem solvers. They have a keen interest in the materials around them and move naturally into activities that involve manipulation of materials, exploration and discovery" (Elementary Science, 1996, p.A1). The inquiry-based approach allows children to become physical with the information they are taught, encouraging them to become personally involved in their learning process.

Instructional media designed by scholars and practitioners in the field of education as well as literature on child psychology and development suggest that children learn best when they are engaged in game play (Curriculum Handbooks for Parents, 2011; Druin, 2002; Fletcher, 2008, Gaver, 1983; Haamaalaainen, 2011; Piaget, 1997). Playing alleviates any anxiety that may be associated with the process of learning and assessment (Parry \& Gregory, 1998), permitting the participants to absorb information with a higher level of efficiency (Heinich, Molenda, Russel, \& Smaldino, 1996). Furthermore, the process of playing an educational game supports the understanding of new ideas and theories, in addition to conventional classroom-based methods of instruction. Information acquisition and anticipated retention can be significantly improved if the learning approach is dynamic and enjoyable. Playing an environmentally educational game would assist children in solidifying the concepts they learn in class, as well as introduce them to an engaging new way of gaining vital knowledge. Furthermore, a game exploring concepts, scenarios, and strategies of environmental preservation can encourage and empower children to become active participants in protecting the planet and promoting environmentally responsible behavior.

What follows below is the discussion of how an environmental game for elementary school children can be designed based on existing research in the field of child development, educational strategies, and on the visual analysis of previously designed environmental games.

\section{Child Development}

According to the literature on child psychology and development, many children learn best through play, as they can engage actively with information (Gaver, 1983; Haamaalaainen, 2011; Piaget, 1997). Both Piaget and Vygotsky have proposed in their many works that children 
develop and learn through a progression of cognitive development phases and through play. By observing his own children, Piaget derived four consecutive stages of cognitive development, where intelligence was progressively formed based on children's interaction with the world around them. For the sake of this research study, this process of phase-based intellectual growth described by Piaget will be referred to as active learning.

Vygotsky discussed ludic [playful] learning processes in child development, specifically learning through the act of play. He suggested that knowledge can be acquired by children during not only the act of playing, but also by doing so with partners of a similar age range - "play [...] is a stage between the purely situational constraints of early childhood and adult thought, which can be totally free of real situation. Thus further cognitive development could not occur without the liberating effects of imaginative play" (Peisach, Hardeman, 1985, p. 233). Moreover, a classroom-based environmental education game could be a way of combining active learning with play, where the children playing will all be in a similar age range.

The age group selected for this study falls into the category of Concrete Operational stage of cognitive development in children, as discussed by Piaget. The child participants in question will pertain to the latest phase of Concrete Operations, transitioning into the Formal Operational stage of development. Participants should have begun forming adult logic patterns, allowing them to rationalize concrete, real-life situations, as well as classify objects as belonging to two or more categories simultaneously. This basic amount of classification and rationalization skills from participants combined with information acquisition skills progressively learned by them in their science classes over a period of four years, should be sufficient for the design process of a visual tool, such as a game to occur.

A typical environmental education game operates on the principle of simulating situations that have either already occurred in the environment and in nature, or can potentially occur as the result of careless human behavior towards the planet (Fisman, 2005). Children in the developmental stage of Concrete Operations will be able to relate hypothetical simulations offered by the game to reality. This allows an environmental game to explore realistic situations 
such as potential environmental threats or strategies for environmental preservation, by utilizing visual mediums like illustration, photography, or even basic three dimensional characters that players can associate themselves with. A simulated environmental situation becomes tangible to children playing the game and has potential to affect their attitudes and awareness during the third stage of their development, because "...in the early years, children view their experiences as personal and immediate; in later years, they become aware of order and continuity in the world extending beyond their personal experience" (Elementary Science, 1996, p.A2). Therefore, by playing an environmental game at the Concrete Operations stage of their cognitive development, children can become familiar with general environmental issues in an engaging and semi-realistic way, increasing their environmental literacy and awareness in the process. In their future, this can lead to conscientious environmental behavior and environmentally responsible actions.

\section{Educational Strategies}

By combining theories of Piaget and Vygotsky, it is possible to look at child development and education from the perspective of learning through play in a step-by-step, phase-based approach. Luckily, contemporary school systems already support the idea of progressive learning and development, which is reflected in their educational systems. Some schools are beginning to implement play and active learning into their curriculum, the province of Alberta, Canada being a prime example. Schools in Alberta also emphasize the importance of environmental awareness and integrate it into the framework of their curriculum to a high degree. Environmental awareness is achieved through environmental education and is crucial to the development of children, as it "promotes the use of higher-order thinking skills, encourages informal experiences in school as well as outdoors [outside of school]...in order to make a contribution to the environment" (Tal, 2005, p.575).

According to Tal, "in order to educate environmentally literate [and active] students, various settings and teaching methods should be employed" (Tal, 2005, p.575). Alberta-based schools introduce ecological conservation issues to their students starting from the fourth grade of elementary school through an inquiry-based approach to learning, where "the outcome of inquiry 
is knowledge" (Elementary Science, 1996, p.A3). Furthermore, "by participating in activities and reflecting on the meaning of what they do, students develop the skills of learning how to learn and achieve depth in their understanding" (Elementary Science, 1996, p.A2). This skill set is supposed to encourage and enhance information acquisition and retention in students by applying a learning triad to their educational process - focus/explore \& investigate/reflect \& interpret. According to the Alberta Education science curriculum, stimulating active inquiry can be done by "providing an initial focus and challenge for learning, by engaging students in developing or adapting a plan of action and by involving students in evaluating results" (Elementary Science, 1996, p.A2). Furthermore, the schools focus on learning actively - "science programs [...] provide opportunities for children to engage in argumentative reasoning that allows them to practice justifying claims, argue different views, understand uncertainty and begin to develop an understanding of how to evaluate scientific evidence" (Focus on Inquiry, 2004, p.16).

Environmental awareness is established in students at an early age with basic concepts and then expanded and explored further as they continue their education. Children are offered choices on which they can base their informed decisions, solving problems in a creative and active way, as opposed to the lackluster system of conventional education, which promotes theoretical memorization of information rather than a practical hands-on approach. Consequently, children gradually develop a set of skills that allows them to become aware of environmental deterioration and preservation matters in a way that is practical and engaging. Such a process of combining active learning with environmental awareness is a sure way to simultaneously foster "an appreciation of the environment, [...] developing knowledge, skills, attitudes, values and a commitment that allows active participation in decision-making" (Tal, 2005, p.575). However, referring back to Vygotsky's research, information acquisition and anticipated retention can be significantly improved if the learning approach is dynamic and enjoyable, for instance as playing an educational game would be. Therefore, adding the act of playing into the mix of active learning and environmental education can be achieved with an environmentally educational game. The process of playing an educational game can support the understanding of new ideas and theories, in addition to classroom-based methods of instruction. 


\section{Game Design for Active Learning}

Ludic activity is proven to encourage and enhance information retention (Heinich, Molenda, Russel, \& Smaldino, 1996), as it provides the player with an opportunity to forget about the act of learning and focus on the act of playing (Peisach, Hardeman, 1985). On a psychological level, information is better perceived and later retained if the educational process involves eustress, or the "positive feelings of enjoyment and excitement that one experiences when engaging with something new and different" (Parry, Gregory, 1998, p. 12) in a non-stressful, non-threatening learning environment. Such an environment of eustress can be created if the learner gains their knowledge through the process of play. Contrary to the above described ways of active learning, conventional methods of education often put children on the spot, making them formulate answers based on memorization in front of a group of their classmates. Such an approach would cause distress to occur in the child's learning environment, causing their "brain to function below peak efficiency" (Parry, Gregory, 1998, p. 12).

On a physiological level, playing a game - even a physically non-active one - still requires personal involvement and full participation from the player - whether they themselves are taking their turn, or observing the other players taking theirs. "The ability to wander among multiple possibilities [...] epitomizes ludic activity. Play is not just a matter of games or entertainment, but rather one of a fluid engagement with myriad opportunities" (Gaver, 1983, p.5). Students learn best when they become personally involved in their learning - not just when they mechanically follow a set of steps or read and hear about things learned and done by others, therefore educational processes "that embody ludic activities [...] encourage exploration, wondering and new forms of playful influence" (Gaver, 1983, p.3). Consequently, an active engagement with the proceedings of an educational game ensures that the player can learn both from their participation and their observation of others. A game exploring concepts, scenarios, and strategies of environmental preservation can encourage and empower children to become active participants in preserving the planet and promoting environmentally responsible behavior as they move through life. 


\section{Visual Analysis of Existing Environmental Games}

In order to design a prototype of an environmental education game, existing environmental education games are to be tested and analyzed. Based on their effectiveness with the child participants, the strongest aspects of the games will be selectively utilized and concentrated on in the design of the Planet Play prototype; the weakest and least desirable aspects of existing environmental games should also to be determined through the data collection process and consequently avoided during the making of the prototype. Considering the vast amount of currently available environmental games and the impossibility of having the children participating in this study experience all of them, a feasible solution would be to examine, categorize and then select a realistic number of games to be tested by the participants. To achieve a higher diversity of feedback about the environmental games from the participants, the types of environmental game presented to them should be as different from each other as possible.

A visual analysis of existing environmental games has been carried out, including all existing games that have been discovered by the researcher. The analysis consists of 50 environmental games, with a focus primarily on non-digital ones; digital [web or video] games are also included in the analysis, yet are not represented in equal proportion compared to analog ones, considering their prevalence on the market in the rough ratio of 9 digital games to 1 analog. For the sake of personal and aesthetic preference, the researcher chose to avoid the already greatly explored field of digital game design for this study, focusing on the seemingly disappearing theme of analog games and their distinctive types. Furthermore, non-digital games are also more effective than digital ones, because "the analogue mode of presentation encodes a graphic context along with the information itself, thus enabling the viewer [user] both to grasp the significance of the message and to place it within recognizable parameters" (Wildbur, \& Burke, 1999, p.6). Moreover, a physical involvement with the materiality of an analog game facilitates a stronger connection between the player and the offered scenario/reality of the game, as opposed to the hypothetical virtuality offered by the digital, two-dimensional arrangement of pixels on a screen.

Existing environmental games were categorized based on their medium [digital/analog/physical], with subcategories about their specifications for each medium. The subcategories included information about the players, the materiality of the game, the design aspect of the game, and its 
context/content. Four games were selected based on their visual and tactical diversity, all four were analog - a card-based game called EcoFluxx, a board-based game called Earthopoly, a strategy-based game called Endango, and a role-play game called Bioviva Mission.

\section{Methods and Procedures}

As stated previously, the aim of this graduate level research study is to explore, design and test a game intended to support children's learning, interest, and willingness to take notions of environmental preservation beyond the school walls. It is essential to integrate active learning methods, such as educational games and play both into the school curriculum and into the lives of children - either as an extra-curricular activity, or better yet as an in-class learning technique, since "...learning games have been found effective in promoting students' knowledge and increasing motivation towards learning" (Haamaalaainen, 2011, p.62). By practicing educational game play in [and out] of the classroom, children can make a smooth transition between their play experience in their earlier pre-school years and their current state of learning at the elementary and middle school level. "They enter school having learned a great deal about their world through play and exploration" (Elementary Science, 1996, p.A1), in other words, they can

apply the skill set they have polished over the years, playing and associating play with entertainment to a more serious setting, where information retention is required; therefore, if information is necessary to be retained, and effectively, it is best done in a manner that is both familiar and non-taxing to the student. Furthermore, games have the potential to offer a constructive approach to learning that allows students to engage and practice learning tasks in a safe environment (Haamaalaainen, 2011). Playing an environmental game would allow children to gain basic experience about hypothetical environmental scenarios and situations, without having to actually physically be subjected to the environmental concerns and issues explored in the game. Because "games may serve as mediation between experience and understanding" (Haamaalaainen, 2011, p.62), playing an environmental game could be the bridge between what children learn in their science class and how that knowledge can be practically applied to reallife situations. 


\section{Role of Children in Research Process}

In order to create an environmental education game that children would respond to positively and genuinely enjoy spending time with, it is best to involve them directly - their input into the design process and feedback on the prototype of the designed game can take the game from purely educational to both educational and enjoyable. For this research study, children will be asked to take on the role of users, testers, and informants, as described in much detail in Druin's research on the Role of Children in the Design of New Technology. It is necessary to ask child participants to test existing environmental education games in order to determine what works and what doesn't work about the games according to the children themselves. "At the start of a project or product design" - in this case prior to designing the Planet Play prototype, it is useful to "observe children using existing technologies" (Druin, 2002, p.17). Children will therefore act as users and testers of existing technologies [games], providing feedback that can be constructively applied to the creation of a prototype that combines all the strengths and ideally none of the weaknesses of the four existing games. Furthermore, "when a child is in the role of tester, extraordinary amounts of time may not be needed to find initial results", and "design directions may not necessarily be expressed directly by children, but may be implied by their actions" (Druin, 2002, p.15\&17). Moreover, "many children [already play games], therefore few skills need to be learned to be included in the technology design process", allowing for the testing to proceed relatively quickly, especially because "children have little patience for what they don't like and they will let technology developers know exactly just that" (Druin, 2002, p.15).

Because "children are incredibly honest and at times harsh in their assessments [of technology]" (Druin, 2002, p.14), involving them in the creation of the Planet Play prototype in the role of informants, should allow the researcher to create "a game close to their own interests, experiences and fantasies, hereby insuring that they would find the game interesting enough to play" (Magnussen, Misfeldt, \& Buch, 2003, p.1) both in class and outside of school with their friends. 


\section{Methods}

Data for this study is planned to be collected in three different ways - a review of the literature, a visual analysis of existing games - with a focus on environmentally related board games, and a series of workshops with students. A game prototype will be designed in collaboration with child participants in between workshop testing phases. The design study will take place at an elementary school in Alberta, Canada, during regularly scheduled class time with 20 to 30 fourth grade students, who will be divided into groups and monitored by session facilitators. The teacher in charge of the class, being most familiar with the students, will supervise the proceedings, as the principal researcher oversees the process. Materials for this research study are a set of questions, four existing environmental games [as discussed in Visual Analysis], nontoxic brainstorming and prototype-making materials and an environmental game prototype developed by the researcher.

The set of environmental questions designed by the researcher will be of an open-ended format, allowing for a qualitative type of response from the participants, and thus a richer and more varied collection of data. Questions will be formulated based on the Alberta Education curriculum, specifically on environmentally related topics composing it, ranging from grade one through to and including grade four. Focusing the questions on existing material is done to achieve a certainty that children will be asked about information they are already familiar with, having continuously built up a base of knowledge and a problem-solving skill set from grade one onwards. Children participating in this study are going to explore the proposed activities both independently and in groups, identically to the program structure that they are exposed to daily in their school classroom (Focus on Inquiry, 2004). Students would have progressively learned starting from grade one - to first follow an approach given to them by their teacher, then to begin developing their own approach to identifying problems and proposing solutions; continuing further by adding informed and logical decisions and recognition of purpose to their problemsolving strategy. Upon completing the fourth grade, students should be able to independently investigate questions and problems and arrive at solutions.

Below follows a brief summary of the intended data collection process. 


\section{Procedures}

The research procedure will consist of six phases. In Phase 1, the researcher will introduce herself and her four session facilitators to the students. She will briefly discuss general concepts of environmental preservation, reminding the students of the material included in their school curriculum. Facilitators will then separate students into small groups of two, asking them to informally interview each other about environmental issues. To initiate the interview process, the researcher will provide question cards, which will have a question side, asking about the environment based on the school curriculum, as well as a blank side for recording answers. Following immediately is Phase 2, where facilitators will organize students into four groups one group per facilitator. Each group will be invited to reflect upon an environmental issue provided to them by the group leader [facilitator]. Facilitators will ask guiding questions and record the answers and feedback into graphic organizers such as mind maps or flow charts. Students will be asked to contribute opinions and knowledge about environmental issues in the form of verbal and visual associations. Phase 3 will consist of playing environmental games. Facilitators will administer the four games discussed in the Visual Analysis part of this paperone game per group. The games will occur simultaneously, allowing students the possibility to experience four different types of game play. If some games last longer than others, they will be ended early, since the purpose of this phase is to give child participants exposure to various types of play. Similarly to Phase 2, Phase 4 will consist of students reflecting and brainstorming. Facilitators will ask guiding questions about the games that were just played, recording feedback into graphic organizers, as the researcher oversees the sessions.

The researcher will analyze the data gathered in Phases 1-4 to create a prototype of an environmental game, based on the experiences and feedback provided by the participants. The prototype-making stage of this study is intended to be between 2-4 weeks, keeping the visual and tactile aspects of the game prototype to a minimal, conceptual quality so as to allow further modification and refining upon completing Phases 5 and 6, when the prototype will be tested. In Phase 5, research facilitators will administer the environmental game prototype to their groups. All groups will play variations of the same game, each with varying aspects of environmental awareness as well as different styles of game play [such as a board based game, open-ended 
question/answer cards, strategy, and role play/simulation]. After playing the four different game prototypes, participants will be asked for their feedback once more. Facilitators will ask guiding questions about the game experience, recording the answers and feedback into graphic organizers. The game prototype will then be refined according to the feedback from students, its main intention - to move between presenting information and visually persuading the audience (Frascara, 2004), so that the audience can understand and practice environmentally responsible actions.

\section{Design of Prototype}

In designing the Planet Play prototype, its visual and material aspect should be derived from three areas - the visual analysis of existing environmental education games, participants' feedback on these games, and the literature on design of visual communications, specifically information design.

As mentioned previously in Visual Analysis of Existing Environmental Games, existing environmental education games have been collected, analyzed and categorized into a visual analysis based on their similarities and differences. The visual and material aspects of games is specifically pertinent to this section of the research, since it is the look and feel of existing environmental education games that would influence the design of the Planet Play prototype, as opposed to the conceptual aspect of the games. As discussed in Educational Strategies, the conceptual aspect of Planet Play will be based not just on existing games and the literature on aesthetic means of design, but mainly on the education curriculum of the schools that practice active, inquiry-based learning. The prototype of the game "should be used to build a sense of purpose, passion, and opportunity" (Fletcher, 2008, p.2) in children, therefore "the aesthetic aspect of a design influences the effect this design has on the intended audience, and must therefore be carefully planned and considered" (Frascara, 2004, p.77).

The literature discusses a variety of approaches to successfully visualizing information - design of an educational game falls into the category of information design and communications design, areas heavily dominated by Tufte and Frascara. Certain commonalities can be observed in their 
research regarding effective ways of information and communications design. It is proposed that because we live in sensory and cognitive worlds, experiencing visual systems everyday (Banks, 1998), the game prototype should follow coherent systematic patterns throughout typographically and pictorially. In other words, if for instance the prototype aims at being hyper realistic, it would utilize photography and would thus be consistently photographic in its visual language. According to Cronin and Prosser, photography can be employed to stimulate a strong emotional response, it is easily accessible and interpretable for everyone, photography has an informative and aesthetic value, and reflects and identifies reality far more accurately than drawings, diagrams, illustrations, etc (Cronin, Prosser, 1998). However, because "photography is a very selective sample of reality" (Harper, 1998), it "is not strong enough by itself to support a claim. Captions next to photographs greatly influence the photograph's contextual effect and meaning" (Winston, Prosser, 1998). Moreover, to create a dialog between text and image in the game prototype, it would be necessary to implement a textual component [such as a caption] to support the visual (Harper, 1998), because "words on and around graphics are highly effective" (Tufte, 1983, p. 185). Using photography is one of the potential visual mediums in Planet Play, yet is by no means a finalized graphic decision, as all possibilities will be explored and evaluated throughout the data collection process.

During testing of four different environmental games, the participant' feedback will be recorded into graphic organizers, thus offering the researcher insight into the associative thinking processes triggered in children by playing these games; collecting feedback into graphic organizers - such as mind maps - allows children to express themselves both verbally and visually, where words and emotions can become substituted by pictures and colors. By offering their feedback in a graphic way, the participants set the visual tone of the future game prototype, enhancing the visual information gathered from the literature on information design as well as from the visual analysis of existing games.

\section{Results}

Results of the research, data collection, and data analysis process will be organized and recorded in the researcher's Master Thesis in the field of Visual Communication Design. So far, the 
literature review has offered a tremendously useful variety of material and insight into the fields of child development, learning actively through play, and the possibilities of designing visual communications in ways that would benefit educational processes in children. Furthermore, the visual analysis of existing games has brought to light the multitude of already existing environmental education games, allowing the researcher to develop a filtering process that focused on four differing games. Both of the above mentioned processes of preliminary research are essential for transitioning into the data collection phase of this project, where child participants will aid with testing the four chosen games and then the game prototype designed in Phase 2. This study is currently awaiting confirmation of the approval of the ethics application regarding use of human participants.

\section{Conclusion}

The intention of this research study is to explore various environmental games and the reactions of children to them, so as to understand how using design as a communication tool can enhance learning. The long-term benefits of playing environmental games are yet to be determined, both because research in this field is relatively young and because educational games are not currently integrated into the schools' core curriculum on a mass scale. Education methods based on inquiry, combined with up-to-date environmental knowledge can produce a strong awareness base in school children, since a double effect would be achieved through not only what is being taught, but also how it is being taught. Adding educational games into this mix would potentially reinforce the knowledge that was acquired by children academically, and simultaneously utilize the principles and practices of exploration, involvement and active learning. Furthermore, allowing the education process to include ludic activity would introduce the idea of entertainment and possibly aid in alleviating any anxiety that can be associated with learning. "Play is not just mindless entertainment, but an essential way of engaging with and learning about our world and ourselves" (Gaver, 1983, p.1). Consequently, environmental education games can be multifunctional, combining the benefit of raised environmental awareness in children with support of existing methods of education in elementary school. 


\section{References}

Active Playground Equipment. (n.d.). Retrieved 2011, from

http://www.apeplayground.com/index.php

Alberta Education - Curriculum Handbooks for Parents 2011-2012. (2011). Retrieved from http://education.alberta.ca/parents/resources/handbook.aspx

Alberta Education Programs of Study - Elementary Science. (1996). Retrieved from

http://education.alberta.ca/teachers/program/science/programs.aspx

Banks, M. (1998). Visual anthropology: Image, object and interpretation. In J. Prosser (Ed.), Imagebased research A sourcebook for qualitative (pp. 9-23). Falmer Press.

Bennett, A. (Ed.). (2006). Design Studies: Theory and Research in Graphic Design (1 ed.). New York, NY: Princeton Architectural Press.

Coble, C. R., \& Brady, G. A. (1977, October). Fun + Games = Learning. Science and Children, 15(2), 15-16.

Cronin, O., \& Prosser, J. (1998). Psychology and Photographic Theory. Imagebased Research A Sourcebook for Qualitative Researchers (pp. 69-83). Falmer Press.

Druin, A. (2002). The Role of Children in the Design of New Technology. Behaviour and Information Technology, 21, 1-25.

Domka, L. (2004). Environmental Education at Pre-school. International Research in Geographical and Environmental Education, 13(313), 258-263.

Fisman, L. (2005, Spring). The Effects of Local Learning on Environmental Awareness in Children: An Impirical Investigation. The Journal of Environmental Education, 36(3), 39-50.

Fletcher, A. (2008). Why Play Games When There's Work to Do? Fun, Games and Social Change. The Free Child Project. Retrieved from http://www.freechild.org/index.htm

Frascara, J. (2004). Communication Design: Principles, Methods, and Practices. New York, NY: Allworth Press.

Frascara, J. (1997). User Centred Graphic Design, Mass Communication and Social Change. Communication. Taylor-Francis.

Gajus-Lankamer, E. (2004). Environmental Education at Polish Gymnasiums. International Research in Geographical and Environmental Education, 13(3), 269-276. 
Gaver, W. W. (1983). Curious things for curious people. History. Retrieved from

http://mars.gold.ac.uk/media/36.gaver.curiousThings.inPress.pdf

Haamaalaainen, R. (2011, March). Using a game environment to foster collaborative learning: a design-based study. Technology, Pedagogy and Education, 20(1), 61-78.

Harper, D. (1998). An Argument for Visual Sociology. In J. Prosser (Ed.), Imagebased research a sourcebook for qualitative researchers (pp. 24-41). Falmer Press.

Heinich, R., Molenda, M., Russel, J. D., \& Smaldino, S. (1996). Instructional Media and Technologies for Learning (5 ed.). Columbus, Ohio: Merrill.

Kam, M., Ramachandran, D., Raghavan, A., Chiu, J., Sahni, U., \& Canny, J. (2006). Practical Considerations for Participatory Design with Rural School Children in Underdeveloped Regions: Early Reflections from the Field. Interfaces (Vol. 32, pp. 25-32). ACM.

Learning, I. I.-based. (2004). Focus on Inquiry. Learning, 122. Retrieved from http://www.lrc.learning.gov.ab.ca

Magnussen, R., Misfeldt, M., \& Buch, T. (2003). Participatory design and opposing interests in development of educational computer games. Learning, CD Rom. University of Utrecht.

Malkus, Amy J. \& Musser, Lynn M., 1993 Children and the New 3 Rs (Reduce, Reuse, Recycle) [microform]: Attitudes toward the Environment / Amy J. Malkus and Lynn M. Musser Distributed by ERIC Clearinghouse, [Washington, D.C.]: http://www.eric.ed.gov/contentdelivery/servlet/ERICServlet?accno=ED357865

Mares, C. (1978). Environmental Awareness and Responsibility: An Innovatory Approach Authors: . In . (Reprinted from Evaluation Quarterly, 1978, 2[1], 91-105)

Parry, T., \& Gregory, G. (1998). Designing Brain-Compatible Learning. United States of America: SkyLight Training and Publishing Inc.

Peisach, E., Hardeman, M. (1985). Imaginative play and logical thinking in young children. The Journal of Genetic Psychology: Research and Theory on Human Development, Vol 146(2), Jun, 233-248.

Piaget, J. (1997). Readings on the development of children. (M. Gauvain \& M. Cole, Eds.)Readings on the of Development Children (p. 371). W.H. Freeman.

Prince, H. (1999). Experiential Environmental Education for Primary Aged Children . In . (Reprinted from Outdoor Education and Experiential Learning in the UK, p. 98, by P. 
Higgins \& B. Humberstone, Eds., 1999, The Barn, Plumpton Old Hall, Plumpton, Penrith, Cumbria CA11 9NP, United Kingdom: Institute for Outdoor Learning)

Takala, M. (1991). Environmental Awareness and Human Activity. International Journal of Psychology, 26(5), 585-597.

Tal, T. (2005). Implementing multiple assessment modes in an interdisciplinary environmental education course. Environmental Education Research, 11(5), 575-601. Routledge.

The Power of Play. (1999, July 1). Psychology Today, Retrieved from http://www.psychologytoday.com

Tufte, E. R. (1983). The Visual Display of Quantitative Information. USA, CT: Graphics Press. Uszynska-Jarmoc, J. (2007, May). Self-esteem and different forms of thinking in seven and nine year olds. Early Child Development and Care, 177(4), 337-348.

Wildbur, P., \& Burke, M. (1999). Information Graphics. Innovative Solutions in Contemporary Design (1 ed.). London: Thames and Hudson.

Winston, B., \& Prosser, J. (1998). "The Camera Never Lies": The Partiality of Photographic Evidence. Imagebased Research A Sourcebook for Qualitative Researchers (pp. 60-68). Falmer Press. 